\title{
The risk of disease transmission to livestock posed by contamination of farm stored feed by wildlife excreta
}

\author{
M. J. DANIELS ${ }^{1}$, M. R. HUTCHINGS ${ }^{1 *}$ AND A. GREIG ${ }^{2}$ \\ ${ }^{1}$ Animal Nutrition and Health Department, Scottish Agricultural College, West Mains Road, \\ Edinburgh EH9 $3 J G$ \\ ${ }^{2}$ Veterinary Science Division, Scottish Agricultural College, Cleeve Gardens, Oakbank Road, Perth PH1 1HF
}

(Accepted 21 January 2003)

\section{SUMMARY}

Livestock feed is susceptible to contamination from wildlife excreta during on farm storage. Pathogens associated with diseases such as paratuberculosis, salmonella and cryptosporidiosis are present in wild rodent and bird excreta. Feed stores on four farms in the east of Scotland were monitored monthly over the winter of $1998 / 9$ to quantify the levels of wildlife faecal contamination. A mean of 79.9 rodent ( $95 \%$ confidence interval: $37.5-165.9$ ) and 24.9 $(14 \cdot 3-41 \cdot 7)$ bird faeces were deposited per $\mathrm{m}^{2}$ of stored feed per month. It was estimated that individual cattle and sheep could encounter 1626 and 814 wildlife faeces over the winter.

A model based on the numbers of infected faeces consumed per annum was used to estimate 'infectious probabilities' $\left(P_{\text {inf }}\right)$ required to account for the reported prevalence of paratuberculosis, salmonella and cryptosporidiosis in sheep and cattle in the east of Scotland in 1998. Based on empirical data for input variables [the number of faeces encountered $\left(F_{e}\right)$, the number ingested $\left(\mathrm{F}_{\mathrm{i}}\right)$ and the prevalence of infection in wildlife species $\left.\left(\mathrm{I}_{\mathrm{p}}\right)\right], P_{\text {inf }}$ estimates ranged from $1.6 \times 10^{-8}$ for cryptosporidiosis in sheep to $8.2 \times 10^{-6}$ for paratuberculosis in cattle. The model suggested that ingestion of feed contaminated by wildlife faeces could account for the prevalence of all three diseases. Wildlife faecal contamination of stored feed should be given serious consideration as a potential source of infection to livestock.

\section{INTRODUCTION}

Livestock feed is susceptible to contamination from rodent and bird excreta during on farm storage. Rats (Rattus norvegicus), house mice (Mus domesticus), wood mice (Apodemus sylvaticus), feral pigeons (Columba livia) and sparrows (Passer domesticus) commonly gain access to feed stores, consume the feed and contaminate it with faeces. As well as the economic losses resulting from feed that is both spilt and consumed by wildlife, there are also health implications for livestock and potentially to humans [1].

\footnotetext{
* Author for correspondence: SAC, Animal Biology Division, West Mains Road, Edinburgh EH9 3JG.
}

Faeces from the rodent and bird species listed may contain the pathogens associated with salmonella and cryptosporidiosis in livestock [2-5]. For example, on 11 farms in England and Wales 46/73 (63\%) of rats were positive for Cryptosporidium parvum detected in their faeces [2].

More recently, rabbits Oryctolagus cuniculus and other wildlife species associated with farms have been implicated in the potential transmission of $\mathrm{Myco}$ bacterium avium subsp. paratuberculosis, the cause of Johne's disease or paratuberculosis [6-8]. There is also evidence that rodents associated with livestock feeds may excrete M. a. paratuberculosis (Table 1).

Feed contaminated with wildlife faeces could pose an important risk to housed livestock because, unlike 
Table 1. Prevalence (proportion) of three diseases of livestock for which pathogens are found in four species of wildlife known to contaminate livestock feed stores

\begin{tabular}{llll}
\hline \hline Species & Paratuberculosis & Salmonellosis & Cryptosporidiosis \\
\hline House mouse & $-0^{*}$ & $0[9]$ & $0 \cdot 22[3]$ \\
Common rat & $0 \cdot 09^{*}$ & $0 \cdot 02[11]$ & $0 \cdot 63[2]$ \\
Wood mouse & $0 \cdot 03^{*}$ & $? \dagger$ & $0 \cdot 21[3]$ \\
Mean 'rodent' & $0 \cdot 04$ & $0 \cdot 01$ & $0 \cdot 35$ \\
House sparrow & $0^{*}$ & $0 \cdot 23[10]$ & $? \dagger$ \\
Feral pigeon & $0^{*}$ & $0 \cdot 17[10]$ & $? \dagger$ \\
Mean 'bird' & 0 & $0 \cdot 20$ & $? \dagger$ \\
\hline \hline
\end{tabular}

* Beard et al. personal communication. $\dagger$ ?, No data available.

grazing at pasture, animals may not have access to an uncontaminated alternative. Consequently, since livestock presented with rodent contaminated feeds demonstrate only limited avoidance of contamination or rejection of feed, significant quantities (i.e. up to $100 \%$ ) of faeces may be consumed (Daniels and Hutchings, unpublished observations).

Despite the potential risks to livestock consuming contaminated feed, there appear to be no data quantifying the level of contamination entering stored livestock feed. Our overall objective was to investigate the role that wildlife faecal contamination of farm stored feed could play in the epidemiology of paratuberculosis, salmonellosis and cryptosporidiosis - three diseases of livestock reported in the east of Scotland which potentially involve wildlife vectors [12].

This study therefore describes the results of monitoring wildlife faecal deposition at four farms in the east of Scotland with the aims of: (a) quantifying the level of faecal contamination by wildlife of farm stored feed and $(b)$ determining whether ingestion of contaminated feed could account for the prevalence of paratuberculosis, salmonellosis and cryptosporidiosis.

\section{METHODS}

\section{Study farms}

Four farms, two farms in Perthshire and Kinross and two in Angus, were selected as part of a study to investigate the potential role of wildlife (including rodents and birds) in transmitting paratuberculosis to livestock. All farms had a history of paratuberculosis in livestock and M. a. paratuberculosis had previously been isolated from rabbits $[6,7]$. This led to an investigation of the role of other wildlife in the epidemiology of paratuberculosis [8], including birds and rodents potentially contaminating stored livestock feed.

On all four farms cattle were housed indoors during the winter months (November-April inclusive) with access to ad libitum silage supplemented daily with a mean ration of $3.6 \mathrm{~kg}$ of concentrates per head. Sheep were generally overwintered on grazing pasture and supplemented daily with a mean ration of $1.8 \mathrm{~kg}$ of concentrates per head. Stores of feed concentrates were maintained throughout the winter months in farm outbuildings.

Concentrates were stored on the floors of farm buildings as either: ( $a$ ) whole grain barley; $(b)$ pelleted 'nuts' (cattle nuts: wheat, maize gluten, dried grass, palm kernels, rape-seed, molasses, fat, salt, limestone and minerals in order of concentration, and sheep nuts: same composition but with the addition of sunflower); or (c) 'meal' comprising of bruised (i.e. crushed) barley mixed with 'nuts' and added minerals for direct feeding to livestock.

\section{Monitoring wildlife faecal contamination}

On each farm, three plastic trays $(420 \times 600 \times 20 \mathrm{~mm})$ were placed randomly in stores of feed during November 1998-April 1999. Each of the three trays was filled to overflowing with the surrounding dried feed (weighing approximately $1 \cdot 2 \mathrm{~kg}$ ) and the contents emptied monthly. Tray contents were searched for wildlife faeces, the numbers and weights of which were recorded. Trays were then refilled with uncontaminated feed and replaced in a random position.

Although identification between rat and mice faeces and sparrow and pigeon faeces was possible, and these were the most frequently encountered species near grain stores, it was possible that contamination by other species (e.g. wood mice Apodemus sylvaticus 
Table 2. Livestock numbers and confirmed incidence of diseases reported for the east of Scotland in 1998 from Veterinary Investigation Diagnosis Analysis records

\begin{tabular}{llllll}
\hline \hline & Holdings* & $\begin{array}{l}\text { Livestock } \\
\text { numbers }\end{array}$ & $\begin{array}{l}\text { Para- } \\
\text { tuberculosis† } \dagger\end{array}$ & $\begin{array}{l}\text { Salmo- } \\
\text { nellosis: }\end{array}$ & $\begin{array}{l}\text { Crypto- } \\
\text { sporidiosis }\end{array}$ \\
\hline Cattle & 1562 & 190589 & 49 & 4 & 16 \\
Sheep & 1089 & 932451 & 6 & 0 & 3 \\
\hline \hline
\end{tabular}

* Number of agricultural holdings with livestock [12].

$\dagger$ Based on detection of acid fast bacteria by ZN smears.

* Total for all salmonella types including S. dublin and S. typhimurium.

or blackbirds Turdus merula) may have occurred. Consequently, all small mammal faeces were classified as 'rodent' and all avian faeces as 'bird'. The numbers of rodent and bird faeces deposited, were used to provide an estimate of the mean contamination rate of stored feed on the four farms per month. This estimate was then used in analyses of the risk that wildlife faecal contamination could potentially pose in terms of disease transmission to livestock.

\section{Quantifying the risk of disease to livestock from wildlife faecal contamination of stored feed}

The potential disease risk that wildlife faecal contamination of stored feed poses to livestock, was estimated by a simple model which calculated the 'infectious probability' $\left(P_{\text {inf }}\right)$ of faeces necessary to account for the numbers of disease incidents reported for the east of Scotland in 1998. Point estimates for each variable in the model, obtained from empirical data, were first used to calculate probabilities. The sensitivity of the model to each variable around the point estimate used was then tested (as described in 'Statistical analyses' below).

The model used to calculate the 'infectious probability' $\left(P_{\text {inf }}\right)$ of faeces necessary to account for the numbers of disease incidents reported was:

$P_{\text {inf }}=1-(1-P)^{1 / \mathrm{F}_{\mathrm{e}} \times \mathrm{F}_{\mathrm{i}} \times \mathrm{I}_{\mathrm{p}}}$

following [13], where $P=$ the probability of an animal having a confirmed diagnosis for each of the three diseases in the east of Scotland in 1998 (see Table 2). Probabilities were calculated from the number of confirmed submissions to Veterinary Investigation centres [12]. Submissions were reported and recorded as 'incidents' which can refer to either individual animals or herd/flock outbreaks [12]. Thus, probabilities were calculated for the number of confirmed submissions divided by $(a)$ the mean number of holdings associated with cattle and sheep and $(b)$ the total herd or flock size in 1998 (Table 2) [12].

$\mathrm{F}_{\mathrm{e}}=$ the mean number of faeces likely to be encountered per animal per year. For the point estimate, an extrapolation was made from the numbers of faeces recorded in stored feed. The weight of feed in each tray (approximately $1.2 \mathrm{~kg}$ ) was equivalent to one-third of a cow's daily ration of concentrates and two-thirds of a sheep's daily ration on the four farms. Thus for cattle the mean number of wildlife faeces likely to be encountered per animal per year was: the mean number of faeces per tray per month $\times 3$ (to account for daily ration) $\times 6$ (for the number of months animals fed concentrates). For sheep $F_{e}=$ the mean number of faeces per tray per month $\times 1.5$ (to account for daily ration) $\times 6$ (for the number of months animals fed concentrates).

$F_{i}=$ the proportion of faeces ingested per animal per year. Previously the proportions of faeces ingested by cattle and sheep, presented with feeds contaminated at different levels, had been measured on one of the four farms (Daniels and Hutchings, unpublished observations). The lowest level of contamination tested was equivalent to 60 rodent faeces per $1.2 \mathrm{~kg}$ / day. At this level of contamination cattle ingested on average 0.66 of the faeces present and sheep 0.97 . These figures were therefore used for the point estimates for $F_{i}$ for cattle and sheep, which assumed that they would respond similarly to: (a) the levels of contamination encountered in this study and $(b)$ bird faeces as to rodent faeces.

$I_{p}=$ the mean prevalence of infection for rodents or birds. Point estimates were derived from Table 1 which assumed that: (a) the rate of prevalence of disease in wildlife was an estimate of the rate of prevalence in faeces and $(b)$ that one faeces was equivalent to one disease unit.

The infectious probability $\left(P_{\text {inf }}\right)$ may then be used as a measure of the potential for disease transmission 
Table 3. Numbers of faeces deposited per $m^{2}$ per month on three feed types stored on four farms over the winter of 1998-9. Means are shown with $95 \%$ confidence limits in parentheses

\begin{tabular}{|c|c|c|c|c|}
\hline Month & Farm & Feed* & Rodent faeces & Bird faeces \\
\hline \multirow[t]{6}{*}{ Nov. 98} & 1 & $\mathrm{a}$ & $20 \cdot 2(0 \cdot 5-305 \cdot 1)$ & $0 \cdot 0-$ \\
\hline & 1 & $\mathrm{~b}$ & $0 \cdot 0-$ & $2 \cdot 0(0 \cdot 0-13 \cdot 7)$ \\
\hline & 2 & $\mathrm{c}$ & $0 \cdot 0-$ & $8 \cdot 9(1 \cdot 0-47 \cdot 6)$ \\
\hline & 3 & $\mathrm{~b}$ & $0 \cdot 0-$ & $151 \cdot 0(30 \cdot 1-741 \cdot 9)$ \\
\hline & 3 & $\mathrm{c}$ & $1 \cdot 4(0 \cdot 0-34 \cdot 3)$ & $1 \cdot 4(0 \cdot 0-11 \cdot 0)$ \\
\hline & 4 & $\mathrm{a}$ & $1 \cdot 6(0 \cdot 0-36 \cdot 1)$ & $0 \cdot 4(0 \cdot 0-6 \cdot 0)$ \\
\hline \multirow[t]{6}{*}{ Dec. 98} & 1 & $\mathrm{a}$ & $34 \cdot 6(1 \cdot 5-512 \cdot 4)$ & $0 \cdot 4(0 \cdot 0-5 \cdot 9)$ \\
\hline & 1 & $\mathrm{~b}$ & $0 \cdot 0-$ & $0 \cdot 0-$ \\
\hline & 2 & $\mathrm{c}$ & $0 \cdot 0-$ & $16 \cdot 1(2 \cdot 5-82 \cdot 5)$ \\
\hline & 3 & $\mathrm{~b}$ & $0 \cdot 0-$ & $88 \cdot 0(17 \cdot 2-434 \cdot 0)$ \\
\hline & 3 & $\mathrm{c}$ & $43 \cdot 0(2 \cdot 0-632 \cdot 5)$ & $34 \cdot 5(6 \cdot 3-172 \cdot 6)$ \\
\hline & 4 & $\mathrm{a}$ & $0 \cdot 0-$ & $0 \cdot 9(0 \cdot 0-8 \cdot 4)$ \\
\hline \multirow[t]{5}{*}{ Jan. 99} & 1 & $\mathrm{~b}$ & $46 \cdot 9(2 \cdot 3-689 \cdot 0)$ & $1 \cdot 7(0 \cdot 0-12 \cdot 3)$ \\
\hline & 2 & $\mathrm{~b}$ & $0 \cdot 0-$ & $0 \cdot 9(0 \cdot 0-8 \cdot 4)$ \\
\hline & 3 & $\mathrm{~b}$ & $0 \cdot 0-$ & $35 \cdot 0(6 \cdot 4-175 \cdot 0)$ \\
\hline & 3 & $\mathrm{c}$ & $44 \cdot 1(2 \cdot 1-649 \cdot 5)$ & $21 \cdot 0(3 \cdot 5-106 \cdot 7)$ \\
\hline & 4 & $\mathrm{a}$ & $4 \cdot 3(0 \cdot 0-75 \cdot 6)$ & $3 \cdot 6(0 \cdot 0-21 \cdot 4)$ \\
\hline \multirow[t]{5}{*}{ Feb. 99} & 1 & $\mathrm{c}$ & $313 \cdot 8(20 \cdot 8-4535 \cdot 8)$ & $1 \cdot 4(0 \cdot 0-12 \cdot 0)$ \\
\hline & 2 & $\mathrm{~b}$ & $0 \cdot 0-$ & $1 \cdot 5(0 \cdot 0-12 \cdot 1)$ \\
\hline & 3 & $\mathrm{~b}$ & $0 \cdot 0-$ & $92 \cdot 0(18 \cdot 0-453 \cdot 6)$ \\
\hline & 3 & $\mathrm{c}$ & $813 \cdot 5(55 \cdot 5-12738 \cdot 6)$ & $12 \cdot 4(1 \cdot 5-59 \cdot 5)$ \\
\hline & 4 & $\mathrm{a}$ & $6 \cdot 7(0 \cdot 0-109 \cdot 9)$ & $5 \cdot 7(0 \cdot 4-31 \cdot 7)$ \\
\hline \multirow[t]{6}{*}{ Mar. 99} & 1 & $\mathrm{~b}$ & $388 \cdot 0(26 \cdot 0-5605 \cdot 0)$ & $9 \cdot 0(1 \cdot 0-47 \cdot 9)$ \\
\hline & 1 & $\mathrm{c}$ & $8 \cdot 0(0 \cdot 0-128 \cdot 7)$ & $86 \cdot 0(16 \cdot 8-424 \cdot 2)$ \\
\hline & 2 & $\mathrm{~b}$ & $0 \cdot 0-$ & $12 \cdot 0(1 \cdot 5-57 \cdot 7)$ \\
\hline & 3 & $\mathrm{~b}$ & $0 \cdot 0-$ & $44 \cdot 0(8 \cdot 2-219 \cdot 0)$ \\
\hline & 3 & $\mathrm{c}$ & $279 \cdot 6(18 \cdot 5-4043 \cdot 4)$ & $3 \cdot 7(0 \cdot 0-21 \cdot 9)$ \\
\hline & 4 & $\mathrm{a}$ & $5 \cdot 0(0 \cdot 0-85 \cdot 5)$ & $63 \cdot 9(12 \cdot 3-316 \cdot 3)$ \\
\hline \multirow[t]{5}{*}{ Apr. 99} & 1 & $\mathrm{~b}$ & $37 \cdot 5(1 \cdot 7-553 \cdot 8)$ & $7 \cdot 5(0 \cdot 7-40 \cdot 5)$ \\
\hline & 2 & $\mathrm{~b}$ & $1 \cdot 2(0 \cdot 0-31 \cdot 1)$ & $2 \cdot 9(0 \cdot 0-18 \cdot 1)$ \\
\hline & 3 & $\mathrm{~b}$ & $0 \cdot 0-$ & $7 \cdot 0(0 \cdot 6-38 \cdot 1)$ \\
\hline & 3 & $\mathrm{c}$ & $105 \cdot 9(6 \cdot 4-1539 \cdot 5)$ & $2 \cdot 0(0 \cdot 0-13 \cdot 7)$ \\
\hline & 4 & $\mathrm{a}$ & $24 \cdot 3(0 \cdot 8-363 \cdot 9)$ & $18 \cdot 9(3 \cdot 1-96 \cdot 3)$ \\
\hline
\end{tabular}

* a, grain; b, concentrates; c, meal (see text for details).

to occur via the faecal-oral route, i.e. as $P_{\text {inf }}$ decreases so the potential of the faecal-oral route as a mode of transmission increases.

\section{Statistical analyses}

Wildlife faeces data were normalized by $\log (x+1)$ transformation [14]. The types of feed were unbalanced between farms and months since existing farm management practices were monitored rather than manipulated. Therefore residual maximum likelihood (REML) [15] was used to estimate the mean treatment effects (month, farm and feed type) and their interactions on faeces density. The Genstat REML option
[16] was used which approximates standard errors of the differences for the parameters. Wald tests from the REML routine were used to determine significant differences. The Wald statistic $(W)$ was quoted along with the relevant degrees of freedom and the probability value (compared to a $\chi^{2}$ distribution) for the effects [16]. Log backtransformed means were presented with $95 \%$ confidence limits (due to the restriction on backtransforming S.E.M.s; [14]).

The sensitivity of the model used to predict $P_{\text {inf }}$ was tested with respect to the point estimates used for $F_{e}, F_{i}$ and $I_{p}$ for all three diseases. To illustrate, for paratuberculosis in cattle (based on cattle numbers not holdings), the sensitivity of the model to variation 
Table 4. Estimated probability of infection by ingesting a contaminated rodent or bird faeces, required to account for the reported incidence of diseases in cattle and sheep in the east of Scotland in 1998

\begin{tabular}{lllll}
\hline \hline & $\begin{array}{l}\text { Paratuberculosis } \\
\text { 'rodent' }\end{array}$ & $\begin{array}{l}\text { Salmonellosis } \\
\text { 'rodent' }\end{array}$ & $\begin{array}{l}\text { Salmonellosis } \\
\text { 'bird' }\end{array}$ & $\begin{array}{l}\text { Cryptosporidiosis } \\
\text { 'rodent' }\end{array}$ \\
\hline Cattle & & & & \\
Holdings & $1 \cdot 0 \times 10^{-3}$ & $2 \cdot 7 \times 10^{-4}$ & $4 \cdot 8 \times 10^{-5}$ & $3 \cdot 7 \times 10^{-5}$ \\
Numbers & $8 \cdot 2 \times 10^{-6}$ & $2 \cdot 2 \times 10^{-6}$ & $4 \cdot 0 \times 10^{-7}$ & $3 \cdot 0 \times 10^{-7}$ \\
Sheep & & $-*$ & - & $1 \cdot 4 \times 10^{-5}$ \\
Holdings & $2 \cdot 4 \times 10^{-4}$ & $-*$ & - & $1 \cdot 6 \times 10^{-8}$ \\
Numbers & $2 \cdot 8 \times 10^{-7}$ & - & - & \\
\hline \hline
\end{tabular}

* - Where the incidence of a disease is zero no estimate can be calculated.

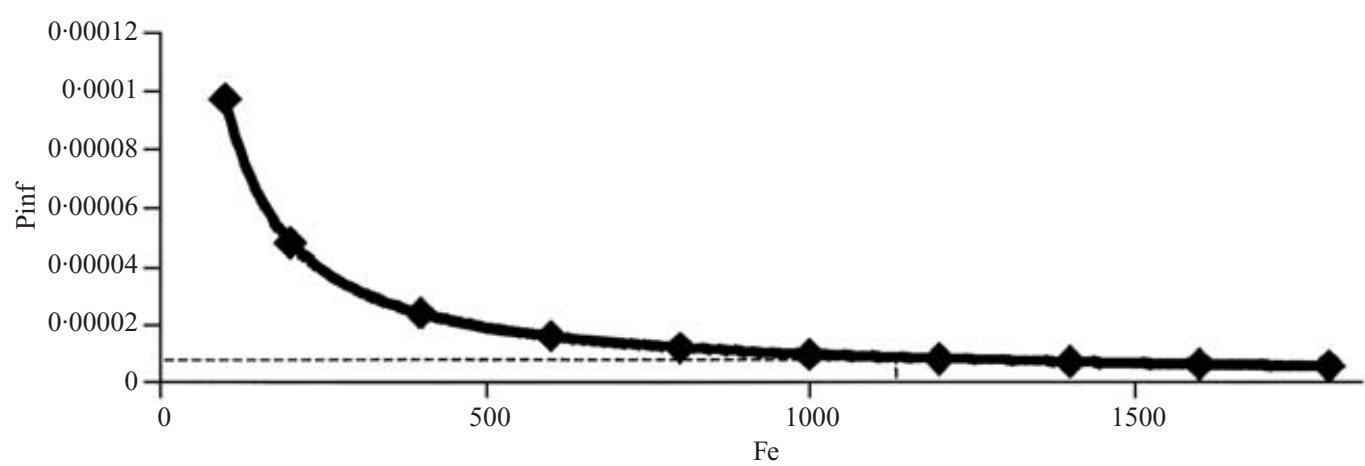

Fig. 1. Estimated probabilities of infection $\left(P_{\text {inf }}\right)$ required account for the reported incidence of paratuberculosis in cattle (numbers) in the east of Scotland in 1998, in relation to the number of faeces encountered per cow per year $\left(\mathrm{F}_{\mathrm{e}}\right)$. The value of $P_{\text {inf }}$ obtained in Table 4 from the point estimate of $\mathrm{F}_{\mathrm{e}}$ is indicated by dashes. Equation of the line: $y=0 \cdot 0097 x^{-1}$.

in $\mathrm{F}_{\mathrm{e}}$ was determined using the point estimates for $\mathrm{F}_{\mathrm{i}}$ and $\mathrm{I}_{\mathrm{p}}$ and recording the values for $P_{\text {inf }}$ predicted by varying the number of rodent faeces encountered per animal per year from 400 to 2200 (i.e. around the point estimate of 1188). The sensitivity of the model to variation in $F_{i}$ was determined using the point estimates for $\mathrm{F}_{\mathrm{e}}$ and $\mathrm{I}_{\mathrm{p}}$ and recording the values for $P_{\text {inf }}$ predicted by varying the proportion of faeces ingested per animal per year from $0 \cdot 1$ to $1 \cdot 0$ (i.e. around the point estimate of $0 \cdot 66$ ). The sensitivity of the model to variation in $I_{p}$ was determined using the point estimates for $\mathrm{F}_{\mathrm{e}}$ and $\mathrm{F}_{\mathrm{i}}$ and recording the values for $P_{\mathrm{inf}}$ predicted by varying the mean prevalence of infection for rodents from $0 \cdot 01$ to $1 \cdot 0$ (i.e. around the point estimate of $0 \cdot 04)$.

\section{RESULTS}

\section{Monitoring wildlife faecal contamination}

Rodent faeces were deposited at all farms (Table 3), with an overall mean of 79.9 (95\% confidence interval: $37 \cdot 5-165 \cdot 9)$ faeces $/ \mathrm{m}^{2}$ feed per month. There was a significant difference between months $(W=20 \cdot 5$, D.F. $=5 ; P<0 \cdot 01$, with a general increase in the rate of contamination from November to February, followed by a general decline towards April. There was significant variation between farms $(W=33 \cdot 0$, D.F. $=$ $3 ; P<0 \cdot 01)$ and also for feed types $(W=12 \cdot 1$, D.F. $=2$; $P<0.01)$, with more faeces deposited in meal than grain, and more in grain than concentrates. There was a significant interaction between farms and feed types ( $W=6 \cdot 2$, D.F. $=2 ; P<0 \cdot 05)$ with meal on one farm (3) attracting higher levels of contamination than on other farms and feed types.

Bird faeces were deposited at all farms (Table 3), with an overall mean of 24.9 (95\% confidence interval: $14 \cdot 3-41 \cdot 7)$ faeces $/ \mathrm{m}^{2}$ feed per month. There was a significant difference between months $(W=12 \cdot 5$, D.F. $=5 ; P<0 \cdot 05)$, again with an increase in faecal deposition rates from November to February, followed by a decline towards April. There was also significant variation in contamination levels between farms $(W=18 \cdot 3$, D.F. $=3 ; P<0 \cdot 01)$ and a significant interaction between farms and months $(W=32 \cdot 5$, 


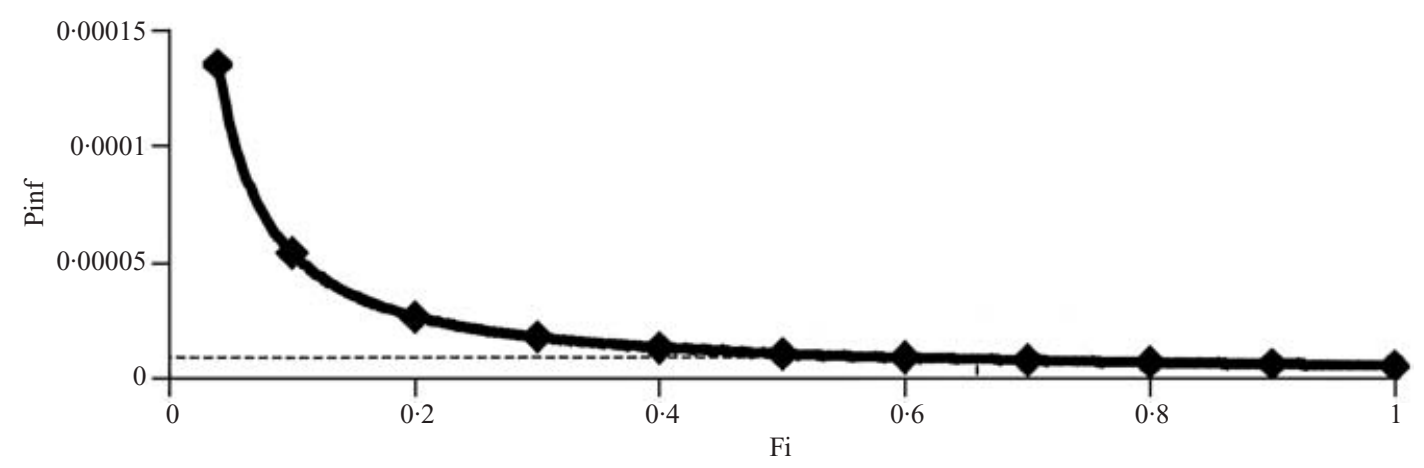

Fig. 2. Estimated probabilities of infection $\left(P_{\text {inf }}\right)$ required to account for the reported incidence of paratuberculosis in cattle (numbers) in the east of Scotland in 1998, in relation to the proportion of faeces ingested per cow per year $\left(\mathrm{F}_{\mathrm{i}}\right)$. The value of $P_{\text {inf }}$ obtained in Table 4 from the point estimates of $\mathrm{F}_{\mathrm{i}}$ is indicated by dashes. Equation of the line: $y=0 \cdot 000005 x^{-1}$.

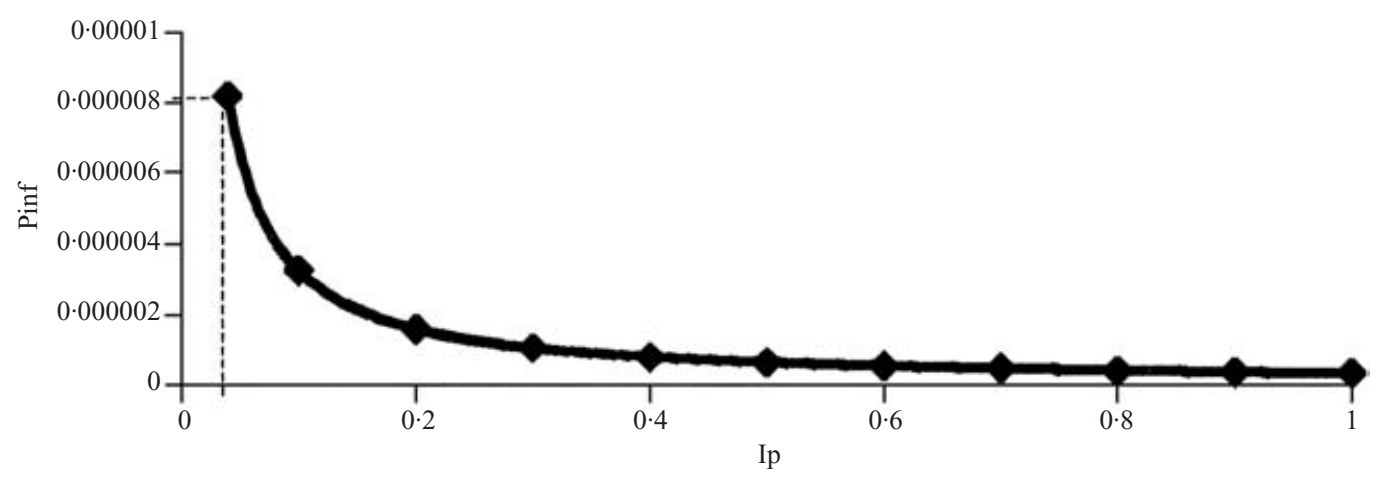

Fig. 3. Estimated probabilities of infection $\left(P_{\text {inf }}\right)$ required to account for the reported incidence of paratuberculosis in cattle (numbers) in the east of Scotland in 1998, in relation to the proportion of faeces ingested per cow per year $\left(\mathrm{I}_{\mathrm{p}}\right)$. The value of $P_{\text {inf }}$ obtained in Table 4 from the point estimates of $F_{\mathrm{i}}$ is indicated by dashes. Equation of the line: $y=0 \cdot 0000003 x^{-1}$.

D.F. $=14 ; P<0 \cdot 01)$ with some farms attracting higher contamination levels in certain months than others. However, there was no significant effect of feed type on the numbers of bird faeces encountered $(W=4 \cdot 9$, D.F. $=2 ;$ n.s.). There was a significant interaction between farms and feed types $(W=20 \cdot 5$, D.F. $=2 ; P<$ $0 \cdot 01$ ) with one farm (3) attracting disproportionately higher contamination in concentrates than in other feed types or other farms.

\section{Quantifying the risk of disease to livestock from wildlife faecal contamination of stored feed}

Based on the mean contamination level found in feed stores on the four farms, the number of faeces likely to be encountered $\left(\mathrm{F}_{\mathrm{e}}\right)$ by cattle were estimated as: 1226 rodent and 400 bird faeces per year. For sheep $F_{e}$ was estimated as 613 rodent and 201 bird faeces per year. From the point estimates of $F_{i}$, the proportion of faeces ingested ( 0.66 for cattle and 0.97 for sheep), it was calculated that individual cattle could ingest
809 rodent faeces and 264 bird faeces per year, and sheep 595 rodent and 195 bird faeces per year.

Based on these empirical data, the estimated 'infectious probabilities' of faeces needed to account for the numbers of disease incidents reported in the east of Scotland in 1998 are presented in Table 4, based on both the numbers of holdings and the total herd/flock. The low probabilities associated with faeces ingestion accounting for prevalence of disease, suggested that ingestion of contaminated feed could account for the prevalence of all reported paratuberculosis, salmonellosis and cryptosporidiosis in cattle and sheep. For example, an 'infectious probability' as low as $8 \cdot 2 \times$ $10^{-6}$ per ingested rodent faecal pellet could adequately account for the prevalence of paratuberculosis in cattle in the east of Scotland (based on the number of individual cattle) (Table 4).

Sensitivity analyses around the three point estimates for all diseases, produced negative power curves where increasing the values of $F_{e}, F_{i}$ and $I_{p}$ resulted in a disproportionate reduction in $P_{\text {inf }}$ (i.e. the lower the 
estimates for $F_{e}, F_{i}$ and $I_{p}$ the more sensitive the model). In the illustrated example of paratuberculosis based on cattle, varying the values of $F_{e}$ and $F_{i}$ by $10 \%$ around the point estimates used in the model (1188 and 0.66 respectively), produced limited variation in $P_{\text {inf }}$ (Figs 1 and 2). However, $P_{\text {inf }}$ was far more sensitive to variation in $I_{p}$ around the point estimate used (0.04), with a reduction in $\mathrm{I}_{\mathrm{p}}$ causing a disproportionately greater increase in $P_{\text {inf }}$ (Fig. 3). However, increasing the value used in the model for prevalence of infection in rodents above 0.04 resulted in a less than proportionate decrease in the estimated probability of infection $\left(P_{\text {inf }}\right)$ required to account for the reported incidence of paratuberculosis in cattle in the east of Scotland in 1998.

\section{DISCUSSION}

The first objective of this study was to quantify the level of faecal contamination entering farm stored feed. The results indicate that thousands of wildlife faeces entered livestock feed on each of the four farms over the winter months monitored. Contamination rates were highest between November and February, presumably when natural food for rodents and birds is at its lowest. Given that all stored feed is consumed by the end of the winter, we estimate that individual cattle and sheep could encounter on average a total of 1626 and 814 wildlife faeces in supplementary feed concentrates respectively.

The type of feed stored influenced the quantity of rodent contamination present. Assuming that rodent faecal depositions occurs in direct proportion to time spend feeding, then rodents appeared more likely to feed in stores of mixed meal as opposed to grain or concentrates alone-when a choice of meal and another feed type was present on a farm. Nevertheless, all feed types stored were contaminated by rodents over the course of the winter. For birds, contamination was equally likely to occur in all feed types. The variation recorded between farms and the interaction between farms and feed types is likely to be the result of differences in the number of rodents and birds present on individual farms rather than the type, area or way feed was stored.

These results suggest that large numbers of rodent and bird faeces are presented to livestock in supplementary feed. If livestock do not actively discriminate against most faeces in meal or concentrates (Daniels and Hutchings, unpublished observations), then the only way to reduce faeces ingestion would be to reduce feed contamination.

The second aim of this study was to estimate the risk contaminated feed posed in terms of potential disease transmission to livestock. Even if the more conservative figures for disease incidence are assumed (i.e. those based on the numbers of holdings as opposed to individual animals - Table 2), then the estimated infectious probabilities $\left(P_{\text {inf }}\right)$ reported here could still account for the number of recorded incidences of all the diseases tabulated. In other words, the reported incidence of these diseases could theoretically be accounted solely for on the basis of infection resulting from ingestion of wildlife faecal contaminated feed. For example, the estimated infectious probability of $8.2 \times 10^{-6}$ for paratuberculois in cattle (based on individual animals - Table 4), means that if only 1 in 122000 (i.e. $1 / 8 \cdot 2 \times 10^{-6}$ ) rodent faeces ingested by cattle in the east of Scotland resulted in disease, then this would still account for all reported cases.

The infectious probabilities $\left(P_{\text {inf }}\right)$ estimated here are based on the assumptions that each faeces from an infected wild animal represents a risk directly related to disease prevalence in that species. For species where the prevalence estimate $\left(I_{p}\right)$ is based on faeces, for example cryptosporidiosis in mice [3], this assumption is valid. However, where this assumption has to be made in the absence of data on wildlife faeces the disease risk may be under or overestimated. With regards to paratuberculosis for example, livestock excrete M. a. paratuberculosis at different levels depending on the stage of disease [17]. Consequently, not all faeces produced from infected wildlife will be infected, and some may carry higher numbers of viable organisms than others (as for example as found in wild rabbits (Daniels et al., unpublished observations)).

The model used to predict the infectious probability of wildlife faeces needed to account for disease prevalence in livestock, produced negative power curves for the three variables measured in all three diseases investigated. The model was thus particularly sensitive to changes at low values for the variables measured $\left(F_{e}, F_{i}\right.$ and $\left.I_{p}\right)$. In paratuberculosis in cattle, for example, the predicted infectious probabilities were robust to variation around the point estimates derived from empirical data for both the number of faeces encountered and the proportion of those faeces ingested - since estimates for these variables were relatively high (Figs 1 and 2). However, the model was far 
more sensitive to changes in estimates for the prevalence of paratuberculosis in wildlife - estimated at $0 \cdot 04$ (Fig. 3). This highlights the need to base the model on strong empirical data, especially where values of $F_{e}$, $F_{i}$ and $I_{p}$ are low. In the paratuberculosis example, the point estimate for $I_{p}$ is based on a single study. Due to the high level of sensitivity of the model to small changes in $\mathrm{I}_{\mathrm{p}}$, the related $P_{\text {inf }}$ value should be treated with caution. However, varying $\mathrm{I}_{\mathrm{p}}$ from $0 \cdot 01$ to 0.99 results in $P_{\text {inf }}$ values of between $3.28 \times 10^{-5}$ and $3.64 \times 10^{-7}$, highlighting the fact that at either extreme the faecal-oral route of disease transmission could still account for the disease prevalence in livestock.

In conclusion, we have demonstrated that livestock feed stored on the ground is susceptible to contamination by rodent and bird faeces and that ingestion of feed contaminated by wildlife faeces is a significant potential route of diseases such as paratuberculosis, salmonella and cryptosporidiosis infection to livestock.

\section{ACKNOWLEDGEMENTS}

We thank the landowners of the four farms for their cooperation in providing access to land and buildings during the study. Also Helen Gartner, V.L.A., Weybridge for assistance in supplying livestock and disease surveillance data and Dave Allcroft for statistical advice. Dennis Henderson, Pip Beard, Karen Stevenson, Mike Sharp and Ilias Kyriazakis provided useful comments on earlier versions of the manuscript. The work was supported by a grant from the Scottish Executive Rural Affairs Department.

\section{REFERENCES}

1. Hinton $\mathrm{MH}$. Infections and intoxications associated with animal feed and forage which may present a hazard to human health. Vet J 2000; 159: 124-38.
2. Webster JP, Macdonald DW. Parasites of wild brown rats (Rattus norvegicus) on UK farms. Parasitol 1995; 111 : 247-55.

3. Chalmers RM, Sturdee AP, Bull SA, Miller A, Wright SE. The prevalence of Cryptosporidium parvum and C. muris in Mus domesticus, Apodemus sylvaticus and Clethrionomys glareolus in an agricultural system. Parasitol Res 1997; 83: 478-82.

4. Sturdee AP, Chalmers RM, Bull SA. Detection of cryptosporidium oocysts in wild mammals of mainland Britain. Vet Parasitol 1999; 80: 273-80.

5. Pennycott T. Salmonella, Campylobacter and E. coli in wild birds. In: Zoonotic Diseases of UK WildlifeSeminar Proceedings, British Veterinary Association, 1999.

6. Greig A, Stevenson K, Perez V, Pirie AA, Grant JM, Sharp JM. Paratuberculosis in wild rabbits (Oryctolagus cuniculus). Vet Rec 1997; 140: 141-3.

7. Greig A, Stevenson K, Henderson D, et al. Epidemiological study of paratuberculosis in wild rabbits in Scotland. J Clin Microbiol 1999; 37: 1746-51.

8. Beard PM, Henderson D, Daniels MJ, et al. Evidence of paratuberculosis in fox (Vulpes vulpes) and stoat (Mustela erminea). Vet Rec 1999; 142: 612-3.

9. Healing TD, Kaplan C, Prior A. A note on some Enterobacteriaceae from the faeces of small wild British mammals. J Hyg 1980; 85: 343-55.

10. Goodchild WM, Tucker JF. Salmonellae in British wild birds and their transfer to domestic fowl. B Vet J 1968; 124: 95-101.

11. Brown CM, Parker MT. Salmonella infections in rodents in Manchester. Lancet 1957; 273: 1277-9.

12. VIDA. Veterinary Investigation Surveillance Report 1998 and 1991-1998. VIDA Section, Veterinary Laboratories Agency, Addlestone, 1998.

13. Hutchings MR, Harris S. Quantifying the risks of TB infection to cattle posed by badger excreta. Epidemiol Infect 1999; 122: 167-74.

14. Zar JH. Biostatistical analysis. New Jersey: PrenticeHall International, 1984.

15. Patterson HD, Thompson R. Recovery of inter-block information when block sizes are unequal. Biomet 1971; 58: $545-54$.

16. Lawes Agricultural Trust. Genstat 5 reference manual. Oxford: Claredon Press, 1993.

17. Sweeney RW. Transmission of paratuberculosis. Vet Clin Nor Am Food Anim Prac 1996; 12: 305-12. 